\title{
MRSS BULLETIN Charts Course for Expanded Coverage
}

\author{
Editorial Board Seeks Your Contributions of Technical Reviews, News, Opinions
}

The establishment of an Editorial Board to facilitate the growth of the size, format, and coverage of the MRS BULLETIN has been announced by Harry Leamy. As a past president of the Society, Leamy will head the board which was developed at the request of MRS President Elton Kaufmann to assist Leamy and Gail Oare of the MRS Headquarters staff to develop fuller and more timely coverage of news and activities of interest to the membership. According to Leamy,"Board members will be responsible for identifying and initiating balanced and timely coverage of materials-related issues for publication in the BULLETIN. Through the collective efforts and talents of the Board and MRS Headquarters editorial staff, we have the opportunity to expand the BULLETIN into a primary communications medium for materials researchers throughout the world...an exciting prospect."

Appointments of Editorial Board members from MRS' international membership is almost complete, Leamy reports, and the roster will be included in the next issue of the BULLETIN. The function of the Board will be to assist members of the Society and other interested professionals in producing articles and editorials that address areas of importance to the broad materials community. Board members will receive and review articles and news items and solicit material they judge to be particularly relevant to readers of the BULLETIN. Scheduling, editorial support, and production activities will be handled at MRS Headquarters.

The following editorial features will be developed over the next few months, and MRS members and other readers a re encouraged to contribute items in any of these areas.

\section{Technical Reviews}

Short technical reviews written in a clear expository manner with abbreviated reference citations and uncomplicated cameraready illustrations are sought. Articles should be a maximum of three published BULLETIN pages (4,500 words or equivalent). Contributions by professionals who can bring perspective to a field of endeavor while describing research of current interest are particularly welcome.

\section{Guest Editorials}

One-page editorials or commentaries on issues of current interest are invited (e.g., see editorial on page 21 of this issue). Voluntary contributions and recommendations of other potential contributors are sought.

\section{Obituaries}

The passing of a colleague should be noted in the BULLETIN in a timely manner by inclusion of an obituary prepared by colleagues who can highlight the career history and contributions of the deceased.

\section{Book Reviews}

Persons interested in providing a thoughful review of a newly published volume on materials science and technology may obtain a list of books made available to the Editorial Board by major science publishers. Reviewers may also suggest other titles they wish to critique.

\section{Personal Notes}

Job changes, awards, promotions, major contract awards, and similar news items of interest to the readership are invited. Members are encouraged to contribute this information (along with the name and telephone number of a person who can be contacted for further information on the story). Readers are also encouraged to tell their organization's public relations department of the BULLETIN's desire to receive news releases from them on similar news items. Photographs related to the stories will also be considered for publication.

\section{Situations Wanted}

The BULLETIN will publish "Situations Wanted" announcements free for MRS members. Experience indicates that use of this confidential forum is an effective means of reaching prospective employers. Messages are to be no more than 75 words and will be published in the earliest available issue of the BULLETIN. Organizations may purchase advertising space for "Positions Available" notices.

\section{Letters to the Editor}

The BULLETIN will print signed letters from readers on topics of interest. The Editor reserves the right to edit submissions for style and space limitations, but will endeavor to preserve the writer's words and intent as far as possible

\section{Society News}

The BULLETIN is still the primary vehicle for reporting news and announcements of MRS activities on the local, national, and international level. Local Sections, Student Chapters, and Committees should be sure to send reports on their activities on a regular basis.

\section{How to Submit Items to the BULLETIN}

Submissions and questions regarding technical reviews, guest editorials, obituaries, letters to the editor, and book reviews should be sent to Harry Leamy, AT\&T Bell Laboratories, 600 Mountain Avenue, Room 2D-346, Murray Hill, NJ 07974; telephone (201) 528-2628 or to any of the Editorial Board members to be announced in the next issue of the BULLETIN.

Articles on and requests for additional information concerning personal notes, situations wanted, and Society news should be sent to Gail Oare, Editor, MRS Bulletin, Materials Research Society, 9800 McKnight Road, Suite 327, Pittsburgh, PA 15237; telephone (412) 367-3003.

Other suggestions and ideas for coverage in the BULLETIN are invited, as the BULLETIN is a service to you. Contact any Editorial Board member, Society Officer, Councillor, Committee member, or MRS staff member to voice your ideas.

\section{LOOKING FOR SOMEONE?}

$$
\begin{aligned}
& \text { A Physicist . . Chemist . . . } \\
& \text { Ceramist . . . Metallurgist . . }
\end{aligned}
$$

More than 2,500 professionals in these fields and others read the MRS BULLETIN for news about the Society and opportunities for professional development. Let them know you're looking for them.

For information on placing your classified advertisement in the BULLETIN, contact Materials Research Society, 9800 McKnight Road, Suite 327, Pittsburgh, PA 15237; telephone (412) 367-3003. 